\title{
Managing Strategic Change of an Organization's Performance: A Case Study of Nzoia Sugar Company, Kenya
}

\author{
Ibrahim Makina*, Robert Keng'ara \\ Department of Strategic Management, School of Business Studies and Economics, Maseno University, Kenya
}

Copyright $\mathrm{O} 2018$ by authors, all rights reserved. Authors agree that this article remains permanently open access under the terms of the Creative Commons Attribution License 4.0 International License

\begin{abstract}
The Kenyan sugar sector is characterized by a series of decline and collapse of state funded milling companies despite massive funding by Government of Kenya. This study sought to establish major causes of Nzoia Sugar Company milling cane below daily target of 7000 tonnes, how strategies are formulated, implemented, controlled, and causes of resistance to change. The study employed census approach with target population of 44 staff members due to convenience and sensitivity of the information in the sugar industry. The research design was descriptive. The data for the study was both primary and secondary. Structured and unstructured questionnaires were the main tools for collecting primary data. Data was analyzed using multiple correlation analysis and descriptive statistics. Data was presented through graphs, pie-charts, frequency tables and figures. The findings showed that most of the workers who resisted change were subordinates comprising $67.7 \%$ while managers who resisted comprised $6.5 \%$. The correlation significance was 0.05 . There was positive correlation between improvement in performance and implementation of the strategies of +0.363 . There was a negative correlation between resistance to change and involvement in resistance to change of -0.33 . The study recommends involvement of all stakeholders in strategy formulation implementation and control.
\end{abstract}

Keywords Change Management, Competitive Advantage, Strategic Change, Resistance to Change, Organization Performance

\section{Introduction}

This chapter looks at the historical background of the sugar industry in Kenya, how it was formed, the regulatory framework and key players in the management of the sector such as Kenya Sugar Board (K.S.B), enabling Acts of Parliament, and the history of Nzoia Sugar Company.

\subsection{Background of the Study}

It is generally recognized that an organization's development whether a project or otherwise is dependent on the effectiveness of management or those with whom the strategic responsibility and decision making rests.

Kenya Sugar Board is the regulatory body of the sugar industry established on $1^{\text {st }}$ April 2002 under the Sugar Act 2001, succeeding Kenya Sugar Authority (K.S.A). The mandate of the Kenya Sugar Board is stipulated in section $4(1)$ and 4(2) of sugar promote the sugar industry, formulated and implemented overall policies.

Kenya has over ten (10) Sugar Companies spread across the country this means that if well manage the country should be self-sustaining in regards to its sugar requirement without necessarily importing. Most of these companies are producing sugar below their capacity which leads to increased debts from the Government; some of them are earmarked for privatization. The Government of Kenya decided to write off all sugar company debts in 2012 with the aim of reducing the burden on to the companies, however, despite this gesture, the company's performance is surprisingly on a downward strand.

Todnem R [1] says that the extent to which an organization is currently achieving its objective will naturally be a driver for change. This is most clearly felt in respect of underperformance, indicating that the current operational strategies and plans are not effective in delivering the required results thus some change is needed.

Todnem R [1] sees management change as a structured and systematic approach to achieving a sustainable change in human behavior within an organization. Change management involves moving employees to new behavior while retaining key competitive advantage particularly competence and customer satisfaction. 
Kenya Sugar Board (K.S.B) is the regulatory body of the sugar industry established $1^{\text {st }}$ April 2002 under the Sugar Act 2001, succeeding the defunct Kenya Sugar Authority (K.S.A). The mandate of K.S.B as stipulated in Section 4(1) and 4(2) of Sugar Act of 2001 is to regulate, develop and promote the sugar industry. It formulates and implements overall policies and plans for the development of industry. It is also mandated to monitor domestic market, identify and advice on any distortions in the sugar market. This means that the Kenya Sugar Board oversees the strategies that are formulated, implemented and controlled by all sugar companies in the country including Nzoia Sugar Company. This is one of the oldest sugar companies in Kenya. It is located in the rural parts of Bungoma County having been established in 1975 by an Act of parliament; under the Companies Act cap 486 of the Laws of Kenya.

Nzoia Sugar Company is located in Western Kenya, approximately $15 \mathrm{~km}$ from Bungoma town. The land area is about 9000 ha of land of which 4000 is covered by nuclear estate. The major objective when it was established was to reduce rural-urban migration, produce white sugar and reduce poverty level. It started cane milling in 1978; Five Cail Babcock (F.C.B) Company provided technical employees and the major financiers are the National Treasury and Industrial Development Bank (IDB)

The major stakeholder is the Government of Kenya as it commands over $98 \%$ of the shareholding portfolio. This means that the nature of the stakeholder is direct. The remaining $2 \%$ is for Five Cail Babcock (F.C.B) and Industrial Development Bank (IDB). The Government appoints the top management. Nzoia Sugar Company falls under the Ministry of Agriculture which appoints the Board of Directors that in-turn appoints the managing director who appoints the Heads of Department (H.O.D), Company Secretary and other managers. The operation starts from the cane planting to harvesting, transportation of cane to the weigh-bridge after that to the factory for milling. The milled sugar is then stored in the warehouses after which it is marked.

The general performance of Nzoia Sugar has not been good. In 1978 when it started there were some subsidies and the tax holdings given to it. The Company picked up initially but it started undergoing economic difficulties which led to the increase of debts to the Government up to KES 7 billion. Farmers were being paid three months after delivering cane which is de-motivating. In 2012 the Government of Kenya decided to write off all the debts of Nzoia Sugar Company.

The Company's strategies are well formulated for example diversification of its products, i.e. production of bottled water, ethanol and power. It also plans to increase milling of sugar cane per day from the current 4000 tons to 7,000 tons per day. However, the major challenge is implementing and controlling these strategies.

Another challenge is political interference; it starts from tendering which takes a lot of bureaucracy, licensing which affects the planned implementation of strategies because
Government has its representative, local directors who are majorly politicians appointed from each constituency that is found in the sugar cane growing zone. Another challenge is marketing. COMESA majorly gives the industry stiff competition. Different COMESA members produce sugar at different costs but they exposed to the same market price among member countries. Infant industries like Nzoia Sugar Company are not protected. Cane plantation requires large parcels of land for realization of economies of scale; however, increase in population around Nzoia Sugar Company, there is sub-division of land into smaller parcels which becomes a threat to the Company survival and competitiveness of its products.

Nzoia Sugar Company has one of the strongest trade unions. This trade union over-protects its members in terms of labour policies for example wage bills. Members are ever agitating for increase of wages while not considering the economic situation or state of the Company which makes it register losses.

\subsection{Statement of the Problem}

Chandler [2] defines strategy as establishment of long terms goals and objectives of organization including taking action and allocating resources for achieving these goals. When strategies are well formulated, implemented and controlled, leads to achievement of objectives. Nzoia Sugar Company has had continuous sub division of land parcels which exposes the Company to danger of survival in the future, many workers resisting changes for example signing performance contract, milling below the targeted tonnage. Some workers are being downsized which is contrary to the initial objectives of the Nzoia Sugar Company among them, job creation. These take place despite many strategies being implemented for example paying farmers on time, writing off Government debts, changing top management, and improvement in the quality of canes. Nzoia Sugar Company has continuously experienced low performance despite many factors and strategies being put in place.

This study sought to determine the management of strategic change of an organization's performance with specific reference to Nzoia Sugar Company; Kenya.

\subsection{Objectives of the Study}

\subsubsection{General Objective}

The overall objective of this study was to management of strategic change of an organization's performance.

\subsubsection{Specific Objectives}

1. To establish major causes of Nzoia Sugar Company performing/ milling below the target 7,000 tonnes per day

2. To establish how strategies are formulated, implemented and controlled.

3. To establish causes of worker resistance to change. 


\subsection{Research Questions}

1. What are the major causes of Nzoia Sugar Company milling below the targeted 7,000 tonnes per day?

2. In what ways are strategies are formulated, implemented and controlled?

3. What are the major causes of resistance to change?

\subsection{Scope of the Study}

The study was based on Nzoia Sugar Company. Nzoia Sugar Company is in Bungoma County; Kenya. It covers several constituencies namely Kanduyi, Sirisia, Kapchai, Bumala, Tongaven, Webuye East, Webuye West. The study aimed at establishing effect of change management of performance of Nzoia Sugar Company. The research method applied was census of which 44 respondents were interviewed.

\subsection{Justification of the Study}

The study was important because it explored performance strategies that could be used by those charged with the change management of any to the Sugar Company's management that are in line with changes in the sector.

The study was also important for accountability. The Government is keen to ensure that the objectives of sugar companies are achieved. The findings and recommendation if implemented would provide a frame work for reference to Government and sugar companies' implementers.

Findings from this study would address strategic performance issues surrounding change management strategies that can be replicated by other sugar companies.

\subsection{Conceptual Framework}

The dependent variable is the organization performance while the independent variable is the change management strategies

The performance of an organization depends highly on the change management strategies of that organization when the two variables works closely lead to success. There are extraneous variables they include internal factors and environmental factors which affect the success of organization, internal factors of an organization includes; employees, shareholders, suppliers' and customers. These factors affect an organization performance. They are also called specific environment.

On the other hand the external environmental factor includes; technological changes, social, economic, political, legal factors.

According to Kothari [3] independent variables that are not related to the purpose of the study, but may affect the dependent variables are termed as extraneous variables. The environmental factor that may affect organizational performance may be due to political, economic, social and technological influence (PEST).

\section{DEPENDENT VARIABLE}

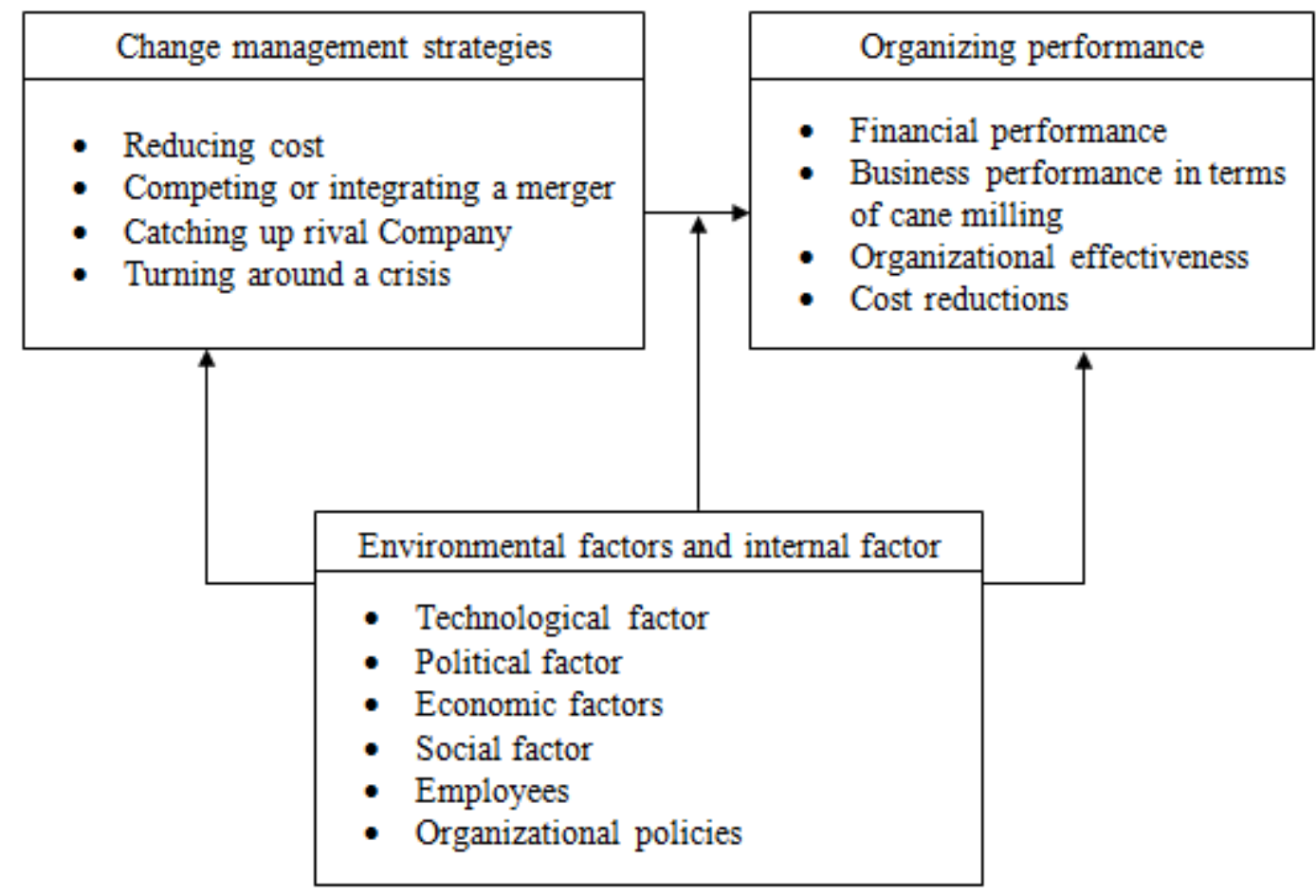

Figure 1. Conceptual framework 


\section{Literature Review}

\subsection{Introduction}

This chapter reviews empirical studies and theoretical.

The review was presented under the following headings: change management strategies, organizational performance and resistance to change and sustaining change. It is a brief overview of sugar industry in Kenya and empirical studies or review on manifestations of change management in the developing counties.

\subsection{Theoretical Literature}

\subsubsection{Change Management Strategies}

Strategic change arises out of the need of organization to exploit existing or emergencies opportunities and deal with trends in the market. This implies the readiness to change within organization and ability to implement proposed change. Most of the organizations have gone through some strategic change as their management has tried to strengthen their existing co-competence and build one's to compete more effectively .Re-engineering, restructuring and innovation have been three kinds of strategic changes pursued in the recent times.

Change management is the systematic method to ensure that an organization's change can be guided in the planned direction, Conducted in a cost effective and efficient manner and completed within the targeted time frame and with desired results Holland Davis [4].

Several factors determine how change is received or embraced by employees within an organization, these factors include organization structure, size, culture, organization maturity, how change is introduced for example centrally, decentrally, how the change was planned, whether it was undertaken on voluntary basis or imposed on the organization and even at which change is exposed on the organization and is expected to take place.

\subsubsection{Review of Empirical Studies}

Maravelas [5] in her research on leadership behavior and change management says that in order to change culture often a radial rethink about core beliefs concerning power leadership is necessary, certainly leaders as change agents are fundamentally in the change process. In her research she found that top manager have a tendency to be viewed by other organizational members in long range terms.
However in her research she did not look at how these strategies are formulated, implemented and controlled with an aim of organizational performance. This means the strategies are formulated by top managers and under rare case they involve juniors.

Holmqvist [6] in his study on leadership behaviour and change management suggests that the rules people learn in organizations, how they know how to act (explicit knowledge) is based on mutual or commonly shared background knowledge. It is responsible to think that this may stem from an understanding of their culture. This means that each set of groups in an organization should be incorporated in strategic formulation, implementation \& control. In his study he did not come out clearly how these changes leads to improvement on performance for organization.

Makin et al [7] carried out research on the effect of change management strategies on organization performance. He concluded that carrying out major change within organizations is impossible without the help and assistance of one or more change agents for example key figures or persons, either external or internal, whose primary objectives is to nurture, encourage and monitor change. This means that change argents are key to the implementation of the strategies.

Elrod II and Tippet [8] known as planned approaches to change argued that change involves a three stage process: firstly, unfreezing current behaviour, secondly, moving to the new behaviour and finally, freezing the new behaviour. The theory however did not look at other aspects like performance. It majorly based on small scale samples and that organizations act under constant conditions that can be taken into consideration and planned for.

Emergent approach to organizational change sees change as so rapid and unpredictable that it cannot be managed from the top down. Instead, it is argued, change should be seen as process of learning, where the organization responds to the external and internal environment changes. Todnem [1] suggests that this approach is more focused on change readiness and facilitating for change than for providing specific pre-planned steps for each change and project and initiative. Several proponents of the emergent school suggest a sequence of actions that organizations should take to increase the chances of change being successful Kotter J.P [9]. 
Table 1. A comparison of three models of emergent change from Todnem (2005)

\begin{tabular}{|c|c|c|}
\hline $\begin{array}{l}\text { Kanter et al. } 10 \text { commandments for } \\
\text { executing change (1992) }\end{array}$ & $\begin{array}{c}\text { Kotter's Eight -Stage process for } \\
\text { successful organizational } \\
\text { transformation (1996) } \\
\end{array}$ & Luecke's seven steps (2003) \\
\hline $\begin{array}{c}\text { Analyse the organization and its need to } \\
\text { change }\end{array}$ & & $\begin{array}{c}\text { Mobilize energy and commitment through } \\
\text { joint identification of business problems } \\
\text { and their solutions }\end{array}$ \\
\hline Create a vision and common direction & Developing a vision and strategy & $\begin{array}{l}\text { Develop a shared vision of how to organize } \\
\text { and manage for competitiveness }\end{array}$ \\
\hline \multicolumn{3}{|l|}{ Separation from the past } \\
\hline Create a sense of urgency & Creating a sense of urgency & \\
\hline Support a strong leader role & & Identify the leadership \\
\hline Line up political sponsorship & Creating a guiding coalition & \\
\hline \multicolumn{3}{|l|}{ Craft an implementation plan } \\
\hline Develop enabling structures & Empowering broad-based action & \\
\hline $\begin{array}{c}\text { Communicate, involve people and be } \\
\text { honest }\end{array}$ & Communicating the change vision & \\
\hline \multirow[t]{5}{*}{ Reinforce and institutionalize change } & Anchoring new approach in the culture & $\begin{array}{l}\text { Institutionalize success through formal } \\
\text { policies, systems, and structure. }\end{array}$ \\
\hline & Generating short-term wins & \\
\hline & $\begin{array}{l}\text { Consolidating gains and producing } \\
\text { more change }\end{array}$ & \\
\hline & & Focus on results not on activities \\
\hline & & $\begin{array}{l}\text { Starts change at the periphery, then let it } \\
\text { spreads to other units }\end{array}$ \\
\hline
\end{tabular}

\subsubsection{Organisational Performance}

Dess and Robinson [11] their research on measuring organizational performance suggests that the subjective performance measures are acceptable when objective data are not available and are probably most appropriate in examining relative performance. They found out that there is high correction between subjective and objective measurers of economic performance in 26 manufacturing organizations. They interviewed top management on the adequacy and validity of management perceptions of organizational performance. They recommended that we compare management of an organizations environment and performance with objective data in order to determine whether management perceptions and valid representations of objectives reality.

According to Carnal [12], the path of organizational change is littered with the best intentions that sometimes never deliver results or value to the organization. Creating successful organizational change is not easy, but there are lessons that can be learned from others who have tried. Poor sponsorship directly impacts the value a project or change delivers to the organization. In the same way that effective sponsorship can mobilize and activate the organization, poor sponsorship can inhibit and delay progress. Employees interpret an absent or inactive sponsor as an indication of how important - or unimportant - the initiative.

\subsubsection{Resistance to Change}

Shaul Oreg [13] proposed that resistance to change is based both on personality and also the context in which the change occurs. In his study he developed and tested a scale called the "resistance to change scale" (RTC) which he conceptualized as a stable personality trait. He found a positive and significant relationship between the individual's RTC score and their affective and behavioral resistance to a particular organizational change they were subjected to. Trust in management was found to have a strong effect, affective, cognitive and behavioral resistance. These findings emphasized importance of good management skills throughout a period of change. In his study he also found out that an increased amount of information given to individuals about the change resulted in a worse evaluation of the change and an increase in willingness to act against it. He hypothesised that if the change has negative implications for the individuals it would not be surprising if hearing more about the change increased resistance to it.

In his research there is high relationship with emergent theory and OD advocates that makes successful decisions about such issues. One of the strategies for reducing resistance to change in employment is to involve the employees in the change or empower them to make changes themselves. Empirical studies have supported the efficacy of this strategy for successful implementation of change, especially within the public sector like Nzoia Sugar Company. Poister and Streib [14] asserts that employee's involvement alone is not sufficient with managers still playing a critical role encouraging and rewarding innovations and expressing support to change. 
Kotter and Schloesinger [10] proposed a more emergent view to tackling employee's resistance, stating that the circumstances of the change and the content of the changes itself will vary largely between organizations and that this should determine the appropriate response. They include; education, participation, facilitation, negotiation and coercion. Terms of strategies for addressing change may be useful to consider the different personality 'type' that employees may correspond to, Warwick D. P [15].

As for Cameron [16], employee resistance to change is common especially in government institutions. Specific areas contributing to resistance from employees include lack of understanding of why the change is happening and "What's in it for me?", Long-tenured employees may be unwilling to support the change, loss of control and ownership of work processes, fear of the future state, including concerns over job security. Resistance is not innocuous - it has long lasting and detrimental effects on the ROI a project delivers. Managing resistance requires both proactive steps to mitigate the sources of resistance and a reactive process for when resistance does occur.

\subsubsection{Sustaining Change}

Implementing a new strategy or a new practice is one of element of changing organizational, dynamics; however evidence suggests that 'initiative decay,' where gains made from change; are lost from the abandonment of new practices.

Buchanan et al [17] in his research argued that this is due to the expenses of longitudinal research as well as the generally negative perception of stability as "inertia" and a lack of responsiveness to the changing environment. They came up with 11 main factors affecting sustainability, as they are shown on the following table.

Table 2. Factors affecting sustainability, from Buchanan et al (2005)

\begin{tabular}{|c|c|}
\hline Category & Outline Definition \\
\hline Substantial & $\begin{array}{l}\text { Perceived centrally, scale ,fit with } \\
\text { organization }\end{array}$ \\
\hline Individual & $\begin{array}{c}\text { Commitment, competencies, promotions, } \\
\text { expectations }\end{array}$ \\
\hline Managerial & Style, approach, preferences, behaviours \\
\hline Financial & Contribution, balances of cost, benefits \\
\hline Leadership & $\begin{array}{c}\text { Setting vision, values, purpose } \\
\text { goals ,challenges }\end{array}$ \\
\hline Organizational & $\begin{array}{c}\text { Policies, mechanisms, procedures, systems, } \\
\text { structures }\end{array}$ \\
\hline Cultural & $\begin{array}{c}\text { Shared beliefs, perceptions, norms, values, } \\
\text { priorities. }\end{array}$ \\
\hline Political & $\begin{array}{l}\text { Stakeholder and coalition power and } \\
\text { influence }\end{array}$ \\
\hline Processual & $\begin{array}{l}\text { Implementation methods, project } \\
\text { management structures }\end{array}$ \\
\hline Contextual & $\begin{array}{l}\text { External conditions, stability, the threats, } \\
\text { wider social norms }\end{array}$ \\
\hline Temporal & Cap timing, pacing, flow of events \\
\hline
\end{tabular}

Source: www.cubec.org.uk
In conclusion change is not a single, but continuous process, but is broken down into a series of steps. The significance of this is that manager will need to consider what strategies, in terms of communication, training, reinforcement; are appropriate for different stages, rather than decide on a single approach that can be applied throughout the process and at the same time remain flexible and reactive to changes as they happen.

\subsection{Conclusion}

Many researchers have deserved that there is a positive correlation between the change management strategies with the performance of organization. Carrying out major changes in organization is impossible without the help and assistance of change agents, Makin et al [9]. The champions of change in an organization are the managers. When change is carried out and well managed by the managers, there will be improvement in performance. Change is not a single but continuous process broken down into a number of different steps. The significance of this is that managers will need to consider what strategies, in terms of communication, training and reinforcement are appropriate for the different stages, rather than decide on a single approach that can be applied throughout the process, and save time, remain flexible and reactive to changes as they happen. All parties in an organization should be incorporated in strategic formulation, implementation and control so that to avoid resistance to change.

\section{Research Methodology}

\subsection{Introduction}

This chapter concerns itself with the descriptive type of research methodology used in the study. Described in this Chapter are the area of the study, study population, population sample, instrumentation and procedures of data collection and analysis.

\subsection{Research Design}

This research is essentially a fact finding research. It therefore adopted a descriptive research design. The researcher intended to describe the effect of change management strategies on an organization performance with particular reference Nzoia Sugar Company. Therefore a case design was adopted to gain in-depth information on the change management strategies employed by Nzoia Sugar Company.

\subsection{Target Population}

The target population was 44 respondents comprising 
managers and unionisable staff. The target heads of departments were from procurement, marketing, agriculture human resource, production, legal audition, finance and strategic planning managers.

\subsection{Sampling Procedures}

The study applied purposive sampling to arrive at Nzoia Sugar Company since Sugar Company management structure is homogeneous across all the sugar companies in Kenya. Nzoia Sugar Company was chosen because of convenience and accessibility.

Census was conducted because the population was small and for convenience.

\subsection{Instrumentation of the Data Collection}

The study used primary data. The data was collected using structured questionnaires. Manager's questionnaires was designed by the researcher and used as the main tool for data collection. The questionnaire composed of close ended and open ended self - administered items. The questionnaires were administered to different managers who are also administrative committee members interview a schedule consisting of both structured and unstructured items some information was collected from information

\subsubsection{Reliability Test for Data Collection Instrument}

Data should measure the intended content in alignment of the research objectives.

\subsubsection{Validity Test for Data Collection}

Data collection instruments were used in order to minimize errors. The correlations were used and tested.

\subsection{Data Analysis and Presentation}

After the information was gathered from the field, it was coded. The data was then tallied and scored for each item, namely, resistance to change, effect of change management strategies in relation to the performance, strategic formulations, implementations and control. Correlation analysis was used to analyze the data using computer software SPSS. Data was presented through parentages, tabulations, graphical illustration of the respondents.

\subsection{Research Ethics}

Before the researcher went to the field he obtained permission to conduct his research from Nzoia Sugar Company. This was after getting an introductory letter from the school's Dean. Data collected shall be used for academic purpose. Any information got is highly confidential. The information collected can be shared with Nzoia Sugar Company on request.

\section{Results and Discussions}

\subsection{Introduction}

This chapter presents the analysis of the effect of change management on organization's performance of Nzoia Sugar Company. Out of 44 questionnaires that were given to the respondents, only 31 were brought back comprising of $70 \%$ of the total respondents.

\subsection{Results}

\subsubsection{Socio-Demographic Features of the Respondents}

The study engaged 31 respondents of which 22 were male accounting for $71.0 \%$ and 9 were female accounting for the other $29.0 \%$. This is illustrated in Table 3 below;

Table 3. Respondents' Gender

\begin{tabular}{|c|c|c|}
\hline & Frequency & Percent \\
\hline Male & 22 & 71.0 \\
\hline Female & 9 & 29.0 \\
\hline Total & 31 & 100.0 \\
\hline
\end{tabular}

Source: Survey data, 2013

The study also engaged respondents according to age as follows, those in age category of below 20 years old accounted for $3.2 \%, 21-30$ years old accounted for $16.1 \%$, $31-40$ years old accounted for $41.9 \%$ which was the majority age group, $41-50$ years old accounted for $38.7 \%$, while there was none above the age of 50 years. This is summarized in Table 4;

Table 4. Respondents' Age

\begin{tabular}{|c|c|c|}
\hline & Frequency & Percent \\
\hline Below 20 years & 1 & 3.2 \\
\hline $21-30$ years & 5 & 16.1 \\
\hline $31-40$ years & 13 & 41.9 \\
\hline $41-50$ years & 12 & 38.7 \\
\hline Total & $\mathbf{3 1}$ & $\mathbf{1 0 0 . 0}$ \\
\hline
\end{tabular}

Source: Survey data, 2013

Concerning the level of education of the respondents, those who concluded at primary school level accounted for $9.7 \%$ of the respondents in the study. Respondents who attained secondary school certificate accounted for another $9.7 \%$ just as the primary school category, while the college level accounted for $61.3 \%$ of the respondents and was the largest group in this study. Finally, the respondents who attained university level accounted for $19.4 \%$ of the respondents. The researcher found out that most of the workers in the Company attained the level of education (college). This information is illustrated in Table 5 below; 
Table 5. Educational Level

\begin{tabular}{|c|c|c|}
\hline & Frequency & Percent \\
\hline Primary School Level & 3 & 9.7 \\
\hline Secondary School Level & 3 & 9.7 \\
\hline College Level & 19 & 61.3 \\
\hline University Level & 6 & 19.4 \\
\hline Total & $\mathbf{3 1}$ & $\mathbf{1 0 0 . 0}$ \\
\hline
\end{tabular}

Source: Survey data, 2013

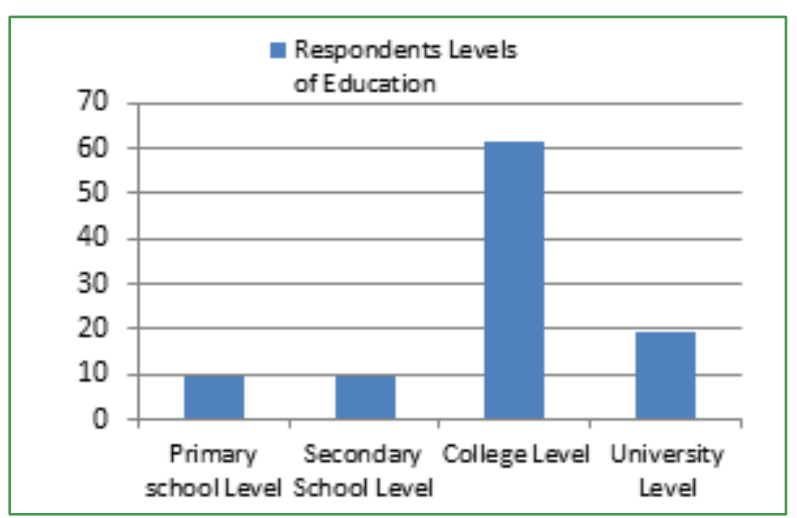

Source: Survey data, 2013

Figure 2. Respondents Levels of Education

The study engaged two categories of staff in almost equal proportions. Out of 31 respondents that took part in this study, 17 were members of management staff, while 14 individuals were members of unionisable staff representing $54.8 \%$ and $45.2 \%$ respectively as illustrated in Table 6 below;

Table 6. Respondent's type of work

\begin{tabular}{|c|c|c|}
\hline & Frequency & Percent \\
\hline Management Staff & 17 & 54.8 \\
\hline Unionisable Staff & 14 & 45.2 \\
\hline Total & $\mathbf{3 1}$ & $\mathbf{1 0 0 . 0}$ \\
\hline
\end{tabular}

Source: Survey data, 2013

Looking at the number of years that the respondents had worked in the Company, $25.8 \%$ of the respondents had worked for less than five years, $22.6 \%$ had worked for a period between 5 to 10 years, $12.9 \%$ had worked for a period between 11 to 15 years and another $12.9 \%$ had worked for a period between 16 to 20 years while another $25.8 \%$ had worked for more than 20 years as shown in Table 7;

Table 7. Length of period worked

\begin{tabular}{|c|c|c|}
\hline & Frequency & Percent \\
\hline Below 5 years & 8 & 25.8 \\
\hline $5-10$ years & 7 & 22.6 \\
\hline $11-15$ years & 4 & 12.9 \\
\hline 16 - 20 years & 4 & 12.9 \\
\hline Above 20 years & 8 & 25.8 \\
\hline Total & $\mathbf{3 1}$ & $\mathbf{1 0 0 . 0}$ \\
\hline
\end{tabular}

Source: Survey data, 2013
The study further established that out of the 31 respondents that took part in the study, 18 individuals had taken part in formulation and implementation of strategies, while 13 individuals had not, accounting for $58.1 \%$ and $41.9 \%$ respectively as illustrated in Table 8;

Table 8. Involvement in formulation and implementation of strategies

\begin{tabular}{|c|c|c|}
\hline & Frequency & Percent \\
\hline Yes & 18 & 58.1 \\
\hline No & 13 & 41.9 \\
\hline Total & $\mathbf{3 1}$ & $\mathbf{1 0 0 . 0}$ \\
\hline
\end{tabular}

Source: Survey data, 2013

The respondents on ranking the level of improvement, $64.5 \%$ of the respondents indicated that improvement was between the range of $0 \%$ to $25 \%, 12.9 \%$ of the respondents stated that improvement was between the range of $26 \%$ to $50 \%, 16.1 \%$ of the respondents stated that improvement was in the range of $51 \%$ to $75 \%$ while the remaining $6.5 \%$ of the respondents stated that improvement was in the range of $76 \%$ to $100 \%$ as shown in Table 9 . The researcher established that after some strategies have been formulated, there was some improvement in the performance. For example, increase of milling of canes from three thousand tones (3,000 tons) to four thousand tones (4,000 tons).

Table 9. Results/improvement in terms of implementation of strategies in terms of performance

\begin{tabular}{|c|c|c|c|}
\hline \multicolumn{2}{|c|}{} & Frequency & Percentage \\
\hline $0-25 \%$ & 20 & 64.5 \\
\hline $26-50 \%$ & 4 & 12.9 \\
\hline $51-75 \%$ & 5 & 16.1 \\
\hline $76-100 \%$ & 2 & 6.5 \\
\cline { 2 - 4 } & Total & $\mathbf{3 1}$ & $\mathbf{1 0 0 . 0}$ \\
\hline
\end{tabular}

Source: Survey data, 2013

Concerning resistance, the study revealed that there was resistance to change. 22 individuals out of 31 respondents for this study were in support of this statement while only 9 individuals were against accounting for $71.0 \%$ and $29 \%$ respectively as illustrated in table 10 . Most of the workers who resisted change were subordinates. They resisted change because of job security. They believed that when they implement they would be down sized.

Table 10. Resistance to change of strategy

\begin{tabular}{|c|c|c|}
\hline & Frequency & Percent \\
\hline Yes & 22 & 71.0 \\
\hline No & 9 & 29.0 \\
\hline Total & $\mathbf{3 1}$ & $\mathbf{1 0 0 . 0}$ \\
\hline
\end{tabular}

Source: Survey data, 2013 
The study established that mostly it was the subordinates who resisted change. $67.7 \%$ of the respondents indicated that subordinate the main group that resisted, $25.8 \%$ attributed resistance to locals while only $6.5 \%$ attributed resistance to the managers as shown in Table 11 and pie chart below;

Table 11. Category of resistance among staff

\begin{tabular}{|c|c|c|}
\hline & Frequency & Percent \\
\hline Managers & 2 & 6.5 \\
\hline Locals & 8 & 25.8 \\
\hline Subordinates & 21 & 67.7 \\
\hline Total & $\mathbf{3 1}$ & $\mathbf{1 0 0 . 0}$ \\
\hline
\end{tabular}

Source: Survey data, 2013

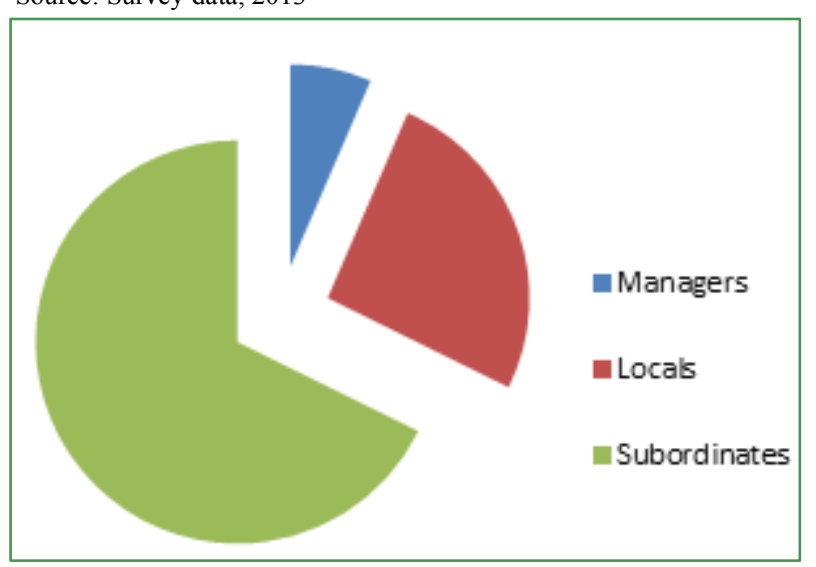

Figure 3. Resistance by group

On investigating whether Nzoia Sugar Company was still serving its original purpose, 21 respondents out of the total 31 supported the statement, while only 10 respondents were not in support accounting for $67.7 \%$ and $32.3 \%$ respectively as illustrated in Table 12 below;

Table 12. Is Nzoia Sugar Serving its original purpose?

\begin{tabular}{|c|c|c|}
\hline & Frequency & Percent \\
\hline Yes & 21 & 67.7 \\
\hline No & 10 & 32.3 \\
\hline Total & $\mathbf{3 1}$ & $\mathbf{1 0 0 . 0}$ \\
\hline
\end{tabular}

Source: Survey data, 2013

The study findings state that there were management strategies changes being implemented at Nzoia Sugar Company. $87.1 \%$ of the respondents stated that there were management strategic changes, while $12.9 \%$ stated that there were no management strategic changes in place as summarized in the Table 13 below;

Table 13. Implementation of management strategies changes by the Company

\begin{tabular}{|c|c|c|}
\hline & Frequency & Percent \\
\hline Yes & 27 & 87.1 \\
\hline No & 4 & 12.9 \\
\hline Total & $\mathbf{3 1}$ & $\mathbf{1 0 0 . 0}$ \\
\hline
\end{tabular}

Source: Survey data, 2013
Looking at the implementation of the changes, out of the 31 respondents, 22 which accounts for $71.0 \%$ are in agreement that the strategy changes are being implemented and only 9 individuals accounting for the remaining $29.0 \%$ were of the opinion that implementation was not being effected as illustrated below in Table 14;

Table 14. Are the changes being implemented?

\begin{tabular}{|c|c|c|}
\hline & Frequency & Percent \\
\hline Yes & 22 & 71.0 \\
\hline No & 9 & 29.0 \\
\hline Total & $\mathbf{3 1}$ & $\mathbf{1 0 0 . 0}$ \\
\hline
\end{tabular}

Source: Survey data, 2013

All the respondents who were interviewed declined to have been part of the group that resisted the changes being implemented by the organization as indicated in Table 15;

Table 15. Were you part of the group that resisted?

\begin{tabular}{|c|c|c|}
\hline & Frequency & Percent \\
\hline No & 31 & 100.0 \\
\hline
\end{tabular}

Source: Survey data, 2013

The significance of correlation was 0.05 .

There was a strong correlation between the management strategy changes implemented by the Company and improvement in performance. The correlation was positive $(+0.363)$.

There was also negative correlation of -0.33 correlations between the resistance to change of strategies and the improvement in performance after the implementation of strategies.

There was also a strong correlation of 0.752 between changes being implemented and the improvement after the implementation of strategies.

\subsection{Discussions}

The study revealed that strategies are formulated, implemented and controlled by the line managers who identify the key performance areas in each department, setting up monitoring and evaluation tools and determining the levels of approvals and accountability. It was revealed that sometimes strategies are formulated by the company management (top management) and controlled by the contact performance and staff appraisals. This is in agreement with the research that Maravelas [5] conducted concerning leadership and behavior and change management, where she said that strategies are formulated by the top management without involving the juniors. The managers are viewed by other organization members as a long range. She recommended that managers and juniors should be brought on board on strategy formulation, implementation and control, so that they own the strategy. 
Concerning the strategies that the company has come up with so as to improve performance, it was discovered that there are many strategies that the company has come up with. They include: restructuring of our growers section into four regions, computerizing service delivery to farmers, formulation and implementation of I.S.O at departmental levels, formulation of five (5) strategic plan, adopting innovative way of achieving goals, performance contracting, salary increment, infrastructure improvement, downsizing of staff and services delivery to farmers all these strategies are meant to improve performance of Nzoia Sugar Company. This is in agreement with the researcher Makin et al [7] who carried out research on the effect of change management strategies on organization performance. He said that carrying out major change within an organization is impossible without the help and assistance of one or more change agents for example, key figures or persons either external or internal, whose major objective is to nurture, encourage and monitor change. This means that all stake holders must be involved in the formulation and implementation of change.

Study revealed some causes or the reasons for resistance to change they include most of the workers feared because of job insecurity, societal culture-believing that the Company belongs to the society and such initiative is to take away the Company from the society, some workers were worried because subordinates resisted because of lack of sensitization. They were not involved in strategic formulation. Trade union interference this was though agitating for pay increment and not accepting downsizing of workers, some workers also resisted change because they had formed opinion that strategic changes will not take off. Some of the causes of resistance to change by workers are in agreement with the research conducted by Shaul Oreg [13]. He proposed that resistance to change is based both on personality and also context in which change occurs. He found out that the positive and significant relationship between individuals and affective resistance to a particular organization. Trust in management has a strong effect, affective, cognitive, and behavioral resistance. In his study, he also found out that an increased amount of information given to individuals about the change resulted in a worse evaluation of the change and an increase willingness to act against it.

The researcher found out that there are many reasons why Nzoia Sugar Company is not achieving its target in terms of performance, among them is there is no diversification of products. The company majorly produces sugar and molasses, the researcher also found out that there is corruption and nepotism, which starts from the tendering where the qualified personnel are not given the tender. The study also revealed that Nzoia Sugar Company is overstaffed which makes the cost of production to be high because of salaries. Politics is also another contributor in the way that members of parliament from the sugar zone constituencies appoint their own people to represent them in the Company so as to push their political agenda. This intern interferes with the performance. Most of the appointments are political.

Another reason is lack of commitment from the management, the management formulates good strategies but when the management formulates good strategies but when it comes to implementing and controlling them they are not committed, these strategies include diversification for examples producing bottled water. Poor supervision is also another cause of underperformance, when strategies are formulated, some worker majorly supervision don't do their work as expected.

The researcher also found that slow adaptation of emergency technologies due to existence of old practices and fear for change is one of the major causes of underperformance because most workers wants status quo to remain. Delayed payments to the farmers due to mismanagement of Company funds also contributes to under-performance, this discourages farmers and they end up taking their canes to other firms for examples Butali, Mumias Sugar, West Kenya who pay their farmers promptly.

The study revealed that one of the major reasons for the sub division of large parcels of land into smaller pieces of land within the sugar zone is that the population has increased thus putting more pressure on available land. This in the long run affects the cane plantation which reduces the tonnage of canes milled per day than the expected tones of 7000 per day.

The study also revealed that some of the possible solutions for the problems facing Nzoia Sugar Company is privatization, but most of the workers did not embrace it because they were fearing loss of their jobs and the fringe benefits that are attached to their jobs and Company.

Study revealed that ethnicity is also a major problem affecting the Company. Some employees are employed on the grounds of ethnicity. Despite one of the major objective of Nzoia Sugar Company was to create job. Employment should not be on the basis of ethnicity.

The study also revealed that the performance of Nzoia Sugar Company has started improving because of paying farmers in time. This actually has discouraged some farmers to take their canes to other competing firms. The payment is usually done in three weeks after the delivery of canes.

The study also revealed that after the Government of Kenya writing off 7 billion Kenya shillings, the production started increasing due to reduced cost of production. Cane milling increased from 2000 tonnes to 3000 per month.

The study also revealed that Nzoia Sugar Company has some strategic plans for 5 years and this includes milling 7,000 tonnes of canes per day, having bottled water and increase production of molasses, other than relying on sugar only. 


\section{Summary, Conclusion and Recommendations}

\subsection{Introduction}

This chapter contains the summary of key findings, Conclusions and recommendations presented in the project. First a summary of key findings, secondly, based on the findings conclusions are derived, thirdly, recommendations and lastly, areas of further research are outlined.

\subsection{Conclusion}

In conclusion, the researcher established that subordinates resisted the implementation of the strategies. This was because they feared their job security. They knew that when they implement changes they will be rendered unemployed.

The researcher also established that managers were the major group that involved in formulation, implementation and control of strategic changes. Most of the workers and managers agreed that Nzoia Sugar Company is not meeting its target of milling 7,000 tonnes of canes per day. This is because of cane poaching and sub division of parcels of land. Most of the respondents were in agreement that Nzoia Sugar Company is still achieving its initial objectives (Creating employment).

\subsection{Recommendations}

Nzoia Sugar Company has the capacity to increase its production and services. It can improve its production / performance starting from the strategy formulation. This can be done by involving all the members on board. Involving managers and workers in the strategy formulation, implementation and control, this will make them to own these changes. Consequently resistance to change will be minimized implementation of down-up leadership style.

It can also improve performance by controlling cane poaching through constant monitoring and supervising its canes. When cane poaching is controlled the number of tones targeted will be achieved. The Company should adhere to the Company strategic plan. The set target will be achieved for example milling 7,000 tonnes per day; this can be done by monitoring and evaluating the strategies timely.

Farmers are also key stakeholders to the Company. When they are motivated by paying them promptly, they will not take their canes to other competing firms like west
Kenya, Mumias Sugar Company. Diversification of products Nzoia sugar has been over-relying on major two products i.e. sugar and molasses.

If it diversifies for example production of bottled water, electricity, this will lead to the spread of risks. Despite the fact that privatization has its limitation but it is one of the best strategies to improve performance this will lead to efficiency and avoid unnecessary cost. It is hard to avoid politics in any organization because it is part of the organization but political interference should be minimized more so about the appointments and tendering.

\subsection{Areas of Further Research}

This research concentrated on effect of change management on organization performance. There is need for further reading on

1. Leadership style and how it affects performance for the entire Sugar Industry.

2. Major causes of resistance to change in the sugar industry in East Africa.

\section{Abbreviations and Acronyms}

\begin{tabular}{cl} 
K.S.B - & KENYA SUGAR BOARD \\
K.S.A - & KENYA SUGAR AUTHORITY \\
I.D.B - & INDUSTRIAL DEVELOPMENT \\
H.O.D - & BANK \\
F.C.B - & FIVDS CAIL BABCORTM B \\
COMESA - & COMMON MARKET FOR EAST \\
& AND SOUTHERN AFRICA \\
ISO - & INTERNATIONAL SYSTEM OF \\
KES - & STANDARDIZATION \\
\hline
\end{tabular}

\section{Definition of Terms}

PERFORMANCE - This refers to the changes in operations of the firm in terms of financial, social and environmental aspects in the positive direction.

CHANGE MANAGEMENT - These are structures and systematic approaches to achieving a sustainable change in human behavior within an organization.

STRATEGIC MANAGEMENT - It is the process of moving an organization away from its present state towards some desired future state to increase its competitive advantage. 


\section{Appendix I}

\section{EFFECT OF CHANGE MANAGEMENT STRATEGIES ON ORGANIZATION PERFORMANCE:}

\section{CASE STUDY OF NZOIA SUGAR COMPANY.}

QUESTIONNAIRE TO BE ANSWERED BY TARGET MANAGERS.

The questionnaire is meant to collect data for a study entitled EFFECT OF CHANGE MANAGEMENT STRATEGIES ON ORGANIZATION PERFORMANCE. For which your department is part of the sample. The data forms an integral part of the study. You are therefore kindly asked to complete the questionnaire.

\section{Section I}

Education level (Please tick as appropriate)
[ ] Primary school
[] Secondary school
[ ] College level
[ ] University level

Age bracket (Please tick as appropriate)

[ ] Below 30 years

[ ] 31-40 years

[ ] 41-50 years

[] Above 50 years

Gender
[] Male
[ ] Female

\section{Section II}

For how long have you worked for Nzoia Sugar Company? (Tick once)
[ ] Below 5 years
[ ] 6-10 years
[] $11-15$ years
[ ] Above 20 years

2a) Have you ever been involved in formulation and implementation of strategic change in Nzoia Sugar company?

$$
\text { YES [ ] NO [ ] }
$$

2b) Which strategies did the company come up with so as to improve the performance?

2c) Was there any improvement after implementing those strategies? If yes, by what $\%$ ?

2d) How are these strategies formulated, implemented and controlled?

e) Was there any resistance to change?

[] YES

[] NO 
f) Which group of people or workers resisted most?
[ ] Managers
[ ] Locals
[] Subordinates

g) What could have been the reason for resistance to change (Please explain)

3) In your own opinion is Nzoia sugar company serving its original purpose?

[] YES
[ ] NO
Explain your answer in 3

4) What could have been the reason as to why Nzoia sugar company is not achieving its target in terms of performance?

5) What improvement, if any would you recommend in the strategic performance of Nzoia Sugar company?

\section{Appendix II}

\section{EFFECT OF CHANGE MANAGEMENT STRATEGIES ON ORGANIZATION PERFORMANCE:}

\section{CASE STUDY NZOIA SUGAR COMPANY}

\section{INTERVIEW SHCEDULE TO BE ANSWERED BY THE TARGET COMPANY WORKERS (UNIONISABLE WORKERS)}

This questionnaire is meant to collect data for the study entitled : EFFECT OF CHANGE MANAGEMENT STRATEGIES ON ORGANIZATION PERFORMANCE of which your group of the sample. The data forms an integral part of the study. You are therefore asked to complete the questionnaires. The information provided is purely for purpose of the study and will be treated with strict confidentiality.

\section{Section I}

Education level (Please tick as appropriate)
[] Primary school
[] Secondary school
[ ] College level
[ ] University level

Age bracket (Please tick as appropriate)
[ ] Below 30 years
[ ] 31-40 years
[ ] 41-50 years
[] Above 50 years

Gender

[] Male

[] Female 
1. Which type of work do you do for Nzoia sugar company? (Please specify)

2. For how long have you worked for Nzoia sugar company (tick appropriate)

[ ] Below 5 years

[ ] 11-20 years

[ ] 20 and above years

4a) What are the management changes strategies that are being implemented by the company?

b) Are these changes being implemented by the company improving its performance?

[ ] YES [ ] NO

Explain your answer

5a) Was there any resistance to change of these strategies?

[] YES [] NO

Please explain why?

Which recommendation would you give in terms of strategic changes for the improvement in the performance of Nzoia Sugar Company?

[6] Holmqvist A (1999) The Consecration of Elites in Djursholm, Columbus University Press

\section{REFERENCES}

[1] Todnem R (2005) Organization Change Management : A critical Review, journal of Change management 5,4,pp369-380

[2] Chandler (1962) Encyclopedia of Management Theory, Strategy and Structure; Sage, Editors Eric Kessler, pp. 800-803

[3] Kothari, C. R. (2004). Research Methodology: Methods and Techniques. New Delhi: Wiley. Lares-Mankki, L (2006). Strategy Implementation Bottlenecks: Identification, Analysis and Removal, Lappeenranta University of Technology, Lappeenranta.

[4] Holland, T. and Davis, J. (2002). The challenge of global change for strategy: Opportunities for charting a new course", in Shrivastava, A.H. and Dutton, J. (Eds), Advances in Strategic Management: Responding to a Changing World, Vol. 9, JAI Press. Bachrach et al.

[5] Maravelas A (1992) How to reduce workplace Conflict and Stress
[7] Makin et al (1996) Human factors in organization Resilience - Implications of breaking the psychological contract, The Business Continuity Journal

[8] Elrod 11, P.D and Tippet, D.D (2002) The "Death Valley" of change, journal of organizational change management, 3 . pp. 273-291

[9] Kotter J.P (1995) leading change: Why transformation efforts fail' Harvard Business Review, 73,2, pp. 59-67

[10] Kotter J.P and Schlesinger, L.A (1997) Choosing Strategies for change, Harvard Business Review, 73,2, pp. 106-114

[11] Dess, GG and Robinson, R.B measuring Organizational performance in the absence of objective measures strategic management journal 19854

[12] Canall A. C, (2007) Managing change in an organization; 5th Edition Pearson Ltd England

[13] Shaul Oreg (2003) Leadership and employees' reactions to change: the role of leaders' personal attributes and transformational leadership style 
[14] Poister, T.H and Streib G. (1999) performance measurement in municipal Government: Assessing the state of practice: Public administration review, 59,4, pp, 325-345

[15] Warwick D.P. (1975) A Theory of Public Bureaucracy Cambridge M.A Harvard University Press

[16] Cameron K.S, (2008) A process for changing organizational culture; Ross School of Business University of Michigan

[17] Buchanan (2005) Organizational development and change; The legacy of nineties, Human Resource Management, PP. 20-30

[18] Kenya Sugar Board (Sugar Act 2003) 